University of Nebraska - Lincoln

DigitalCommons@University of Nebraska - Lincoln

Genetic linkage maps of white birches (Betula platyphylla Suk. and $B$. pendula Roth) based on RAPD and AFLP markers

\author{
Tingbo Jiang \\ Northeast Forestry University, tbjiang@yahoo.com \\ Boru Zhou \\ Northeast Forestry University \\ Fuling Gao \\ Northeast Forestry University \\ Baozhu Guo \\ University of Georgia
}

Follow this and additional works at: https://digitalcommons.unl.edu/usdaarsfacpub

Jiang, Tingbo; Zhou, Boru; Gao, Fuling; and Guo, Baozhu, "Genetic linkage maps of white birches (Betula platyphylla Suk. and B. pendula Roth) based on RAPD and AFLP markers" (2011). Publications from USDA-ARS / UNL Faculty. 1268.

https://digitalcommons.unl.edu/usdaarsfacpub/1268

This Article is brought to you for free and open access by the U.S. Department of Agriculture: Agricultural Research Service, Lincoln, Nebraska at DigitalCommons@University of Nebraska - Lincoln. It has been accepted for inclusion in Publications from USDA-ARS / UNL Faculty by an authorized administrator of DigitalCommons@University of Nebraska - Lincoln. 


\title{
Genetic linkage maps of white birches (Betula platyphylla Suk. and $B$. pendula Roth) based on RAPD and AFLP markers
}

\author{
Tingbo Jiang $\cdot$ Boru Zhou $\cdot$ Fuling Gao $\cdot$ \\ Baozhu Guo
}

This article is a U.S. government work, and is not subject to copyright in the United States.

Received: 12 June 2009/Accepted: 30 March 2010/Published online: 16 April 2010

(C) Springer Science+Business Media B.V. 2010

\begin{abstract}
A pseudo-testcross mapping strategy was used in combination with the random amplified polymorphism DNA (RAPD) and amplified fragment length polymorphism (AFLP) genotyping methods to develop two moderately dense genetic linkage maps for Betula platyphylla Suk. (Asian white birch) and B. pendula Roth (European white birch). Eighty $\mathrm{F}_{1}$ progenies were screened with 291 RAPD markers and 451 AFLP markers. We selected 230 RAPD and 362 AFLP markers with 1:1 segregation and used them for constructing the parent-specific linkage maps. The resultant map for $B$. platyphylla was composed of 226 markers in 24 linkage groups (LGs), and spanned $2864.5 \mathrm{cM}$ with an average of $14.3 \mathrm{cM}$ between adjacent markers. The linkage map for B. pendula was composed of 226 markers in 23 LGs, covering $2489.7 \mathrm{cM}$. The average map distance between adjacent markers was $13.1 \mathrm{cM}$. Clustering of AFLP markers was observed on several LGs. The availability of these white birch linkage maps will
\end{abstract}

T. Jiang $(\bowtie) \cdot$ B. Zhou · F. Gao

Key Laboratory of Forest Tree Genetic Improvement and Biotechnology of Ministry of Education, Northeast Forestry University, 26 Hexing Road, Dongli District, Harbin 150040, People's Republic of China

e-mail: tbjiang@yahoo.com

B. Guo

Crop Protection and Management Research Unit, USDA-Agricultural Research Service, University of Georgia, Tifton, GA 31793, USA contribute to the molecular genetics and the implementation of marker-assisted selection in these important forest species.

Keywords Linkage map - Betula platyphylla . Betula pendula . Pseudo-testcross .

Silver birch

\section{Introduction}

White birches, Betula platyphylla Suk. (Asia white birch) and B. pendula Roth (European white birch), are typical pioneer tree species in secondary forest areas of northeastern China. Due to their fast regeneration and growth, white birches play an indispensable ecological role in the colonization of forest lands following harvest or wild fires in this region. They are also valuable for timber industries because of the compact and spotless qualities of their wood. Therefore, many studies have been conducted on the genetic improvement of white birches in China (Li et al. 1995), including wood quality (Tammisola et al. 1995) and insect resistance (Mutikainen et al. 2000).

However, a difficulty faced by researchers in the field of genetic diversity and breeding of tree species, such as silver birches, is the long generation time, which delays the progress of such research. The 
advantage of molecular breeding using markerassisted selection is the possibility to more easily introgress desired alleles from wild or exotic germplasm to breed elite lines. As more marker-tagged traits become available through genetic mapping in these trees, marker-assisted breeding will become a reality and achieve more precise specific trait integration in genetic improvement of forest tree species. Marker-assisted breeding technology could be applied directly to select the progenies according to their genotypes, rather than relying on more traditional methods based on apparent phenotypes.

Several studies have reported the employment of molecular markers in the investigation of genetic relationships of birch (Jiang et al. 2001, 2002) and selection for long fiber trait (Wei et al. 2006). However, there are no reports on genetic linkage mapping and quantitative trait loci (QTL) analysis of Asian white birch. Kulju et al. (2004) reported the development of 23 primer pairs of microsatellite markers for European white birch and 13 primer pairs of SSR (simple sequence repeat) were developed for Asian white birch (Wu et al. 2003). The first genetic map of European white birch was published by Pekkinen et al. (2005) with 16 linkage groups, based on 82 amplified fragment length polymorphisms (AFLP) and 19 microsatellite markers or SSR markers in 30 mapping progenies developed from three unrelated two-generation pedigrees; the total map coverage was $1,561 \mathrm{cM}$.

In this study, we report the construction of a genetic linkage map from $80 \mathrm{~F}_{1}$ progeny from the cross between $B$. platyphylla and $B$. pendula, using randomly amplified polymorphic DNA (RAPD) and AFLP markers and the pseudo-testcross mapping strategy (Grattapaglia and Sederoff 1995; Yin et al. 1996). This will establish a basis for developing a more detailed linkage map and molecular markerassisted breeding for white birch trees.

\section{Materials and methods}

Development of mapping population

Based on RAPD analysis (Jiang et al. 2002), two highly diverse trees were selected as the parental lines for the mapping population development. One is selected from the Asian white birch collection of
B. platyphylla in China, and the other is from the European white birch collection of B. pendula in Finland. Controlled pollinations between the two parental lines were carried out in April 2005 at the white birch breeding orchard, Northeast Forestry University, Harbin, China. Generated hybrid seeds were planted in the greenhouse and the developed young seedlings were transplanted into pots $(6 \times 6 \mathrm{~cm})$ in the spring of 2006. Four hundred hybrid seedlings were obtained and 80 were used as the mapping population for genotyping.

DNA extraction and PCR amplification

Seedling leaves were sampled and stored at $-80^{\circ} \mathrm{C}$ for DNA extraction. Genomic DNA was extracted with a Universal Genomic DNA Extraction Kit (TaKaRa, Dalian, China). For RAPD analysis, a suitable PCR condition was established, and the reaction mix was $20 \mu \mathrm{l}$ including $50 \mathrm{ng}$ DNA, $1 \mu \mathrm{l}$ of $10 \mu \mathrm{mol}$ primer, $0.5 \mu \mathrm{l}$ of $10 \mathrm{mmol} \mathrm{dNTP,} 2 \mu \mathrm{l}$ of $10 \times$ buffer $(100 \mu \mathrm{mol}$ Tris- $\mathrm{HCl}, 500 \mathrm{mmol} \mathrm{KCl}$, $0.8 \%$ Nonidet P40), $2 \mu \mathrm{l}$ of $25 \mathrm{mmol} \mathrm{MgCl}_{2}, 0.2 \mu \mathrm{l}$ of Taq polymerase $(5 \mathrm{U} / \mu \mathrm{l})$. PCR amplification was performed in a MJ Research PTC-200 thermocycler (MJ Research, MA, USA), starting with an initial denaturation step of $94^{\circ} \mathrm{C}$ for $4 \mathrm{~min}$, followed by 40 cycles of $94^{\circ} \mathrm{C}$ for $30 \mathrm{~s}, 36^{\circ} \mathrm{C}$ for $30 \mathrm{~s}$, and $72^{\circ} \mathrm{C}$ for $1 \mathrm{~min}$, with a final extension step at $72^{\circ} \mathrm{C}$ for $7 \mathrm{~min}$. The amplified DNA was subjected to electrophoresis in a $1 \%$ agarose gel (containing $0.02 \%$ ethidium bromide) in $1 \times$ TAE buffer $(0.04 \mathrm{M}$ TrisAcetate, $1 \mathrm{mM}$ EDTA).

\section{Selection of polymorphic primers}

Ten-mer primers with $60-70 \%(\mathrm{G}+\mathrm{C})$ content were used in RAPD analyses. A total of 1,200 RAPD primer sets (Shanghai Sangon, Sanghai, China) were screened preliminarily by using the two parents. In further selection, $10 \mathrm{~F}_{1}$ progeny were included in the screening to check the polymorphisms among the parents and progeny. According to the equation $\eta=1-(1-1 / 2)^{n}$ ( $n$ represents the total number of progeny, and $\eta$ indicates the probability of a specific pseudo-testcross allelic marker to be selected), the probability of a specific pseudo-testcross allelic marker being selected was $99.9 \%$ in this study (Yin et al. 1996). A total of 203 primers of RAPD markers were selected and used to 
genotype the 80 progeny and the two parents. AFLP analysis was carried out as described by Vos et al. (1995) and Myburg et al. (2001) by using the enzyme combination EcoRI/MseI $(+3,+3)$. The EcoRI primers were labeled with IRD700 fluorescent dye (LI-COR, Lincoln, Nebraska). The AFLP products were analyzed on a $6 \%$ denaturing polyacrylamide gel with a LI-COR 4300 DNA analyzer.

Marker value assignment and genetic linkage map construction

The value of each marker produced was assigned according to its presence and absence in each progeny, i.e., if the fragment was present in a progeny, the value of this fragment was designated as an "H"; if the fragment was absent from the corresponding position of a progeny, the value was an "A". The ambiguous and lost fragments were designated as "-". These alleles were subjected to a $\chi^{2}$ test $\left(\chi_{0.05(1)}^{2}=3.84\right)$ to determine whether the inherited alleles of offspring were in compliance with Mendelian segregation ratios, and followed the twoway pseudo-testcross mapping strategy (Grattapaglia and Sederoff 1994). Only the markers with 1:1 segregation were used for the subsequent mapping analysis. The linkage analysis was performed using MAPMAKER/EXP (version 3.0b), and Kosambi's mapping function was used to estimate map distances in centimorgans (cM) (Lander et al. 1987). The mapping markers were assigned to linkage groups using the "group" command under the condition of LOD $\geq 4.0$, recombination rate $\leq 0.35$, and using the "compare" command and the "try" command. After the linkage groups were defined, the linkage maps were generated using Map Draw (version 2.0) (Liu and Meng 2003). AFLP marker distribution was analyzed using a Poisson distribution function described by Young et al. (1999). Analysis indicated that a density of three or more markers in a $10-\mathrm{cM}$ interval represented the lower threshold of the significant deviation from the expected number of markers per interval.

Estimation of the genetic length using the genetic linkage mapping data

The estimated genetic lengths for the two parental birches used in this study, determined by using the genetic linkage mapping data, were derived according to the method reported by Chakravarti et al. (1991). The length of the genetic linkage map was defined as the total length of the linkage groups containing more than four markers per group in a genetic map, which was the linkage map reported in this study (Fig. 3) representing the total chromosomes of $B$. platyphylla or $B$. pendula. The total length of the linkage groups was the length of all linkage groups including groups with two or more markers per group. The estimated genetic length was the sum of the length of each linkage group multiplied by $(m+1) /(m-1)$, in which $m(m \geq 4)$ is the number of markers included in the corresponding linkage group (Chakravarti et al. 1991). Therefore, the coverage of the genetic linkage map reported in this study was the ratio of the length of the genetic linkage map to the estimated genetic length. The total linkage group coverage was the ratio of the total length to the estimated genetic length.

\section{Results and discussion}

Polymorphism of RAPD markers

Of the 1,200 RAPD primers (Sangon, Shanghai, China) surveyed, 203 (16.9\%) primers produced polymorphic bands between the two Betula parents and among the $F_{1}$ progeny, and generated 291 genetic markers ranging from 0.5 to $2.0 \mathrm{~kb}$ in size. For example, one RAPD primer S235 amplification was polymorphic and segregated among the $F_{1}$ progeny (Fig. 1). Among all the 291 segregation markers, 151 allelic markers (51.9\%) come from parent $B$. platyphylla and the remaining 140 markers $(48.1 \%)$ come from the B. pendula side, and 13 markers were present in both parents. A total of 230 of the 291 markers or alleles segregated as 1:1 (presence or absence); 22 segregated as 3:1; two segregated as $1: 3$. Others were found to be distorted from the normal $1: 1$ and 3:1 or 1:3 ratios. Among the $F_{1}$ progeny, there were similar polymorphic allelic markers from each of the parents, B. platyphylla and B. pendula. The distribution of polymorphic markers conformed to the normal expected proportion of a testcross. 
Fig. 1 Amplification and segregation patterns obtained with RAPD primer S235 in the parents Betula platyphylla, B. pendula and the $F_{1}$ progeny. Molecularweight markers in base pairs (bp) are in lanes 1 and 24 ; $B$. platyphylla is in lanes 2 and $25 ; B$. pendula is in lanes 3 and 26; and the $\mathrm{F}_{1}$ progeny are in lanes 4-23 and 27-46

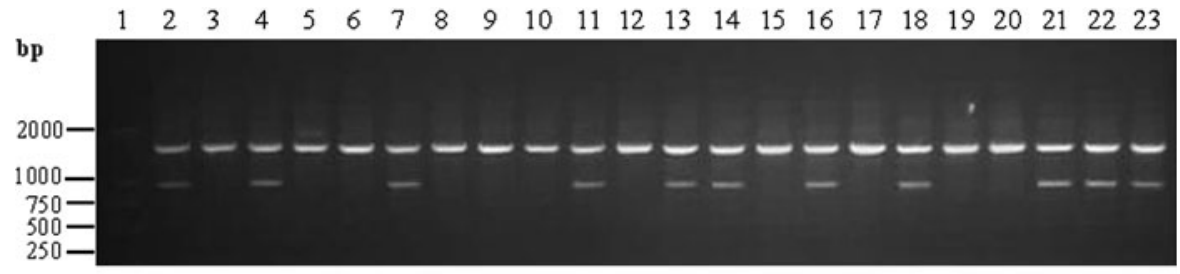

$\begin{array}{lllllllllllllllllllllll}24 & 25 & 26 & 27 & 28 & 29 & 30 & 31 & 32 & 33 & 34 & 35 & 36 & 37 & 38 & 39 & 40 & 41 & 42 & 43 & 44 & 45 & 46\end{array}$

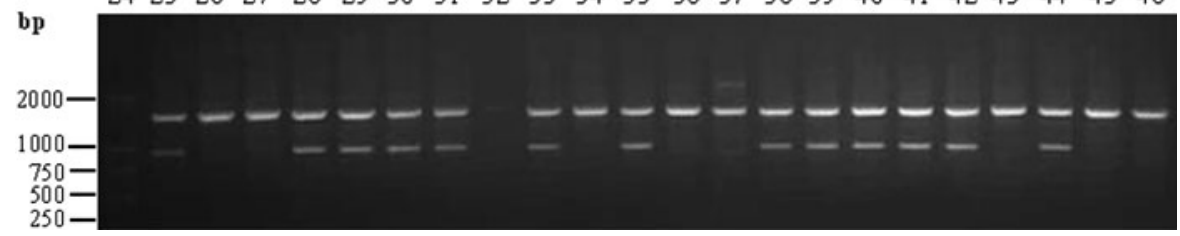

Table 1 Analysis of polymorphisms of AFLP primer combinations for Betula platyphylla

\begin{tabular}{|c|c|c|c|c|c|c|c|c|c|}
\hline Primer (code) & $\begin{array}{l}\text { E-AGG } \\
\text { (E1) }\end{array}$ & $\begin{array}{l}\text { E-ACA } \\
\text { (E2) }\end{array}$ & $\begin{array}{l}\text { E-AAC } \\
\text { (E3) }\end{array}$ & $\begin{array}{l}\text { E-AAG } \\
\text { (E4) }\end{array}$ & $\begin{array}{l}\text { E-AGC } \\
\text { (E5) }\end{array}$ & $\begin{array}{l}\text { E-ACT } \\
\text { (E6) }\end{array}$ & $\begin{array}{l}\text { E-ACG } \\
\text { (E7) }\end{array}$ & $\begin{array}{l}\text { E-ACC } \\
\text { (E8) }\end{array}$ & Total \\
\hline M-CTC (M1) & $8(49)^{\mathrm{a}}$ & $10(46)$ & $10(37)$ & $21(53)$ & - & $17(55)$ & - & - & $66(240)$ \\
\hline M-CAC (M2) & - & $14(57)$ & $5(57)$ & $8(48)$ & - & $14(44)$ & - & - & $41(206)$ \\
\hline M-CTA (M3) & $8(37)$ & $17(67)$ & $16(39)$ & $14(58)$ & - & $13(46)$ & - & - & 68 (247) \\
\hline M-CTG (M4) & $8(41)$ & $15(58)$ & & $11(45)$ & $11(66)$ & $11(45)$ & $10(75)$ & $17(61)$ & $83(391)$ \\
\hline M-CAG (M5) & - & - & - & $9(57)$ & $9(62)$ & - & $12(54)$ & - & $30(173)$ \\
\hline M-CTT (M6) & $11(47)$ & $16(48)$ & - & $14(72)$ & - & - & - & $26(87)$ & 67 (254) \\
\hline M-CTA (M7) & $12(44)$ & $12(82)$ & - & - & $10(59)$ & - & - & - & 34 (185) \\
\hline M-CAA (M8) & - & $20(94)$ & $25(84)$ & - & $17(77)$ & - & - & - & $62(255)$ \\
\hline Total & 47 (218) & 104 (452) & 56 (217) & 77 (333) & 47 (264) & 55 (190) & 22 (129) & 43 (148) & $451(1,951)$ \\
\hline
\end{tabular}

${ }^{\text {a }}$ Numbers of polymorphic AFLP markers between two parental lines; total numbers of amplified fragments in parentheses

\section{AFLP analysis}

We analyzed a total of 34 EcoRI/MseI AFLP primer combinations (Table 1), in which 1,951 allelic markers were identified, ranging from 50 to $500 \mathrm{bp}$ in size (Fig. 2). Of these, 451 were polymorphic and consisted of 232 allelic markers (51.4\%) from B. platyphylla, and $219(48.6 \%)$ came from B. pendula. Among all the 451 segregation markers, 362 were dominant markers, segregating as $1: 1$, and 161 were present only in the paternal lines; 61 polymorphic markers segregated as $3: 1$ or $1: 3$, and 28 polymorphic markers were distorted from the normal $1: 1$ and 3:1 segregation ratios. An average of 13 polymorphic allelic markers was produced from one AFLP primer combination.

Construction of genetic linkage maps

Altogether 592 allelic markers (230 RAPD and 362 AFLP markers) segregating as 1:1 (testcross configuration) were used to construct parent-specific linkage maps using a minimum LOD score of 4.0, resulting in 328 allelic markers for B. platyphylla and 264 allelic markers for B. pendula, respectively. Of the 328 markers for $B$. platyphylla, there were 226 markers linked into 24 linkage groups (LGs) with four or more markers for each LG (Fig. 3a; Table 2), seven LGs with three markers each, three LGs with two markers each, and 75 markers without a group. Therefore, using the LGs with four or more markers per group to represent the chromosomes, the constructed genetic linkage map for B. platyphylla, the Asian white birch, had 24 LGs with 226 markers and spanned $2864.5 \mathrm{cM}$ (Kosambi units) with an average of $14.3 \mathrm{cM}$ between adjacent markers (Fig. 3a). The total length of the linkage groups for $B$. platyphylla was $3062.6 \mathrm{cM}$, including all groups with two or more markers per group (Table 3).

Of the 264 markers for $B$. pendula, there were 226 markers linked into 23 LGs with four or more 
Fig. 2 Amplification and segregation patterns obtained with AFLP primer M-CTG/E-ACA in the parents Betula platyphylla, B. pendula and the $\mathrm{F}_{1}$ progeny. Molecular-weight markers in base pairs (bp) are in lanes 1 and 44; B. platyphylla is in lane 2; $B$. pendula is lane 3 ; and the $\mathrm{F}_{1}$ progeny are in lanes 4-43

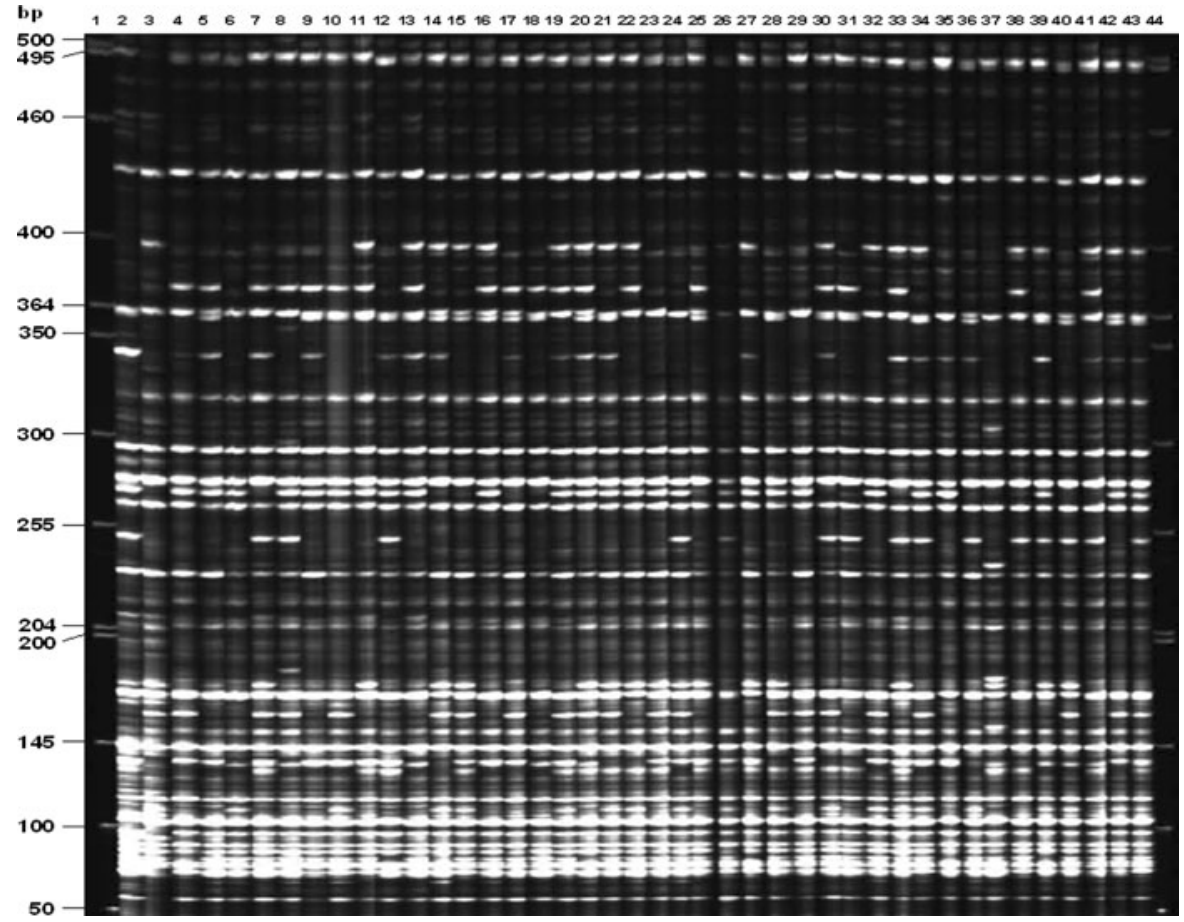

Estimation of genetic length using the genetic linkage mapping data

According to the method proposed by Chakravarti et al. (1991), we estimated the genetic length for both parental species of birches using the genetic linkage mapping data in this study. The linkage map length reported in this study was the total length of the linkage groups containing more than four markers per group (Fig. 3) representing the total chromosomes of B. platyphylla or B. pendula, which were 2864.5 and $2489.7 \mathrm{cM}$, respectively (Table 3 ). The total length of all the linkage groups detected in this study including groups with two or more markers was 3062.6 and $2509.9 \mathrm{cM}$, respectively (Table 3 ). The estimated genetic length was 3552.7 and $3097.2 \mathrm{cM}$, respectively, which was the sum of the length of each linkage group multiplied by $(m+1) /(m-1)$, in which $m(m \geq 4)$ is the number of markers included in the corresponding linkage group (Chakravarti et al. 1991). Therefore, the linkage maps reported in this study (Fig. 3a, b) represent 80.6 and $80.4 \%$ of the estimated genetic length of all chromosomes of B. platyphylla and B. pendula, respectively (Table 3 ).

Genetic linkage maps in plants are usually constructed using segregating populations obtained from within a 10-cM distance (Fig. 3b). 
Fig. 3 Genetic linkage maps of Betula platyphylla Suk. (a) and B. pendula Roth (b), based on RAPD and AFLP markers, obtained through the analysis of $80 \mathrm{~F}_{1}$ progeny generated from the cross between the parental lines. A pseudo-testcross mapping strategy was used in combination with the RAPD and AFLP genotyping to construct the linkage maps. Numbers on the left of each linkage group are Kosambi map distances in $\mathrm{cM}$. The codes on the right side of each linkage group are the names of markers composed of primer name and polymorphic DNA band length
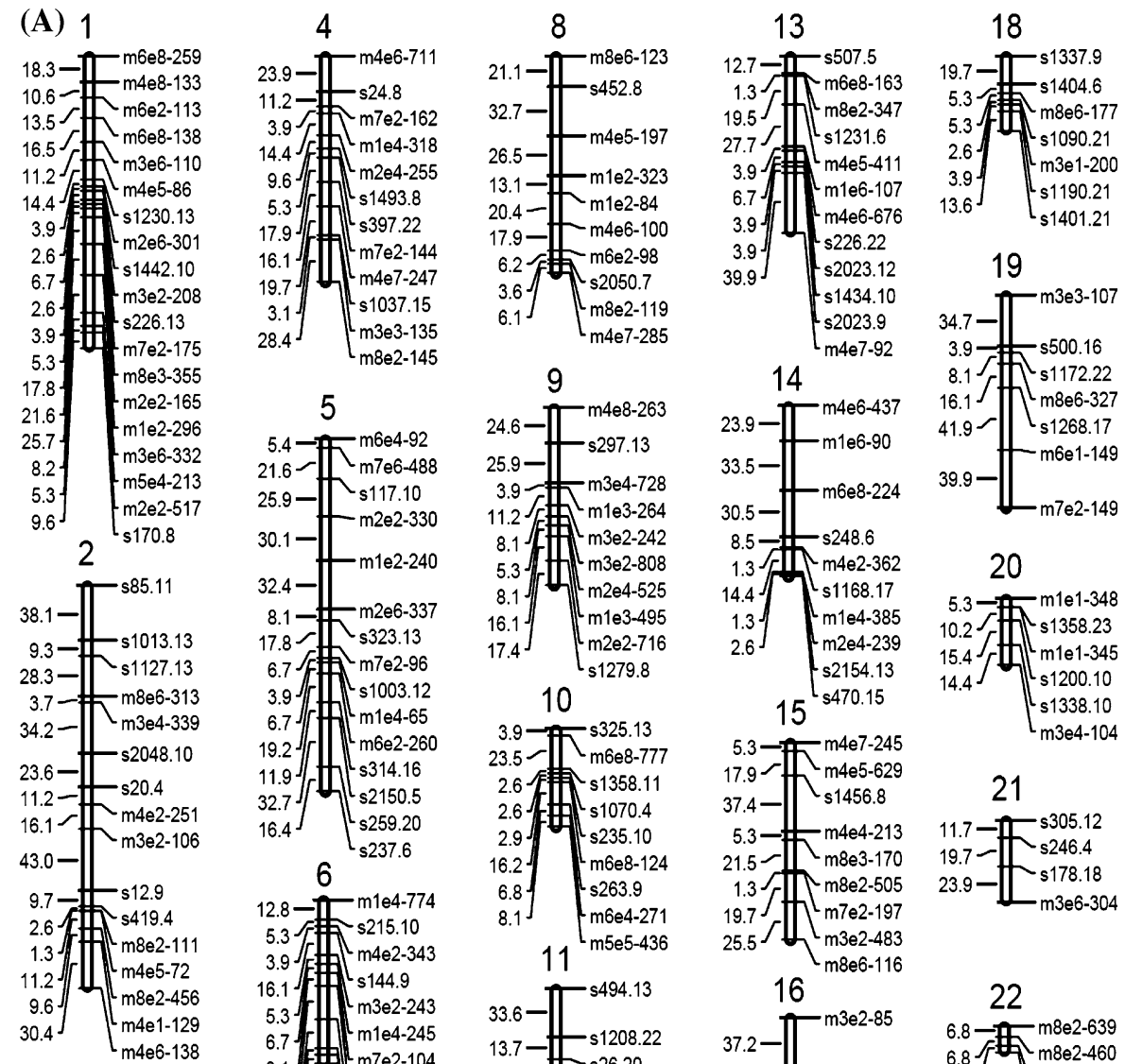

6.7 .

11.9 -

$\left.\begin{array}{l}11.9 \\ 32.7\end{array}\right]\left[\begin{array}{l}s 314.16 \\ s 2150.5\end{array}\right.$

$\left.\begin{array}{l}32.7 \\ \hline\end{array}\right]\left[\begin{array}{l}s 259.20 \\ s 237.6\end{array}\right.$

12.8

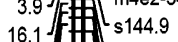

$\left.\begin{array}{c}5.3\end{array}\right]-\frac{m e 2-243}{m 3}$

6.7 m1e4-245

$8.1)\left[\begin{array}{l}m 7 e 2-104 \\ s 241.17\end{array}\right.$

3

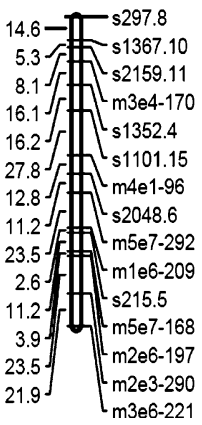

10

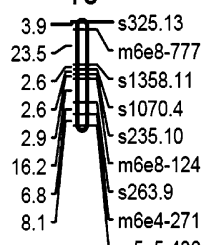

11

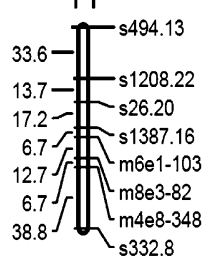

12

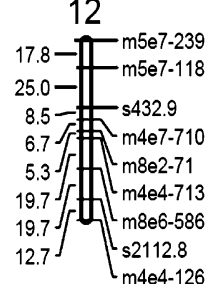

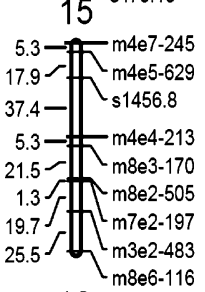

$16 \pi^{m 3 e 2-85}$

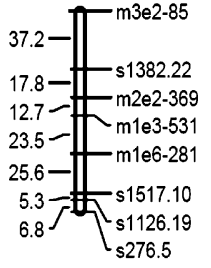

17

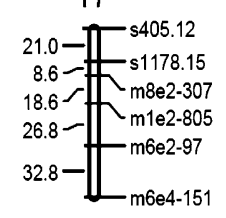

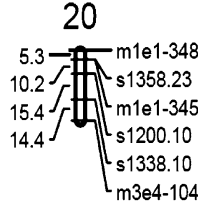

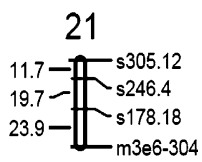

22

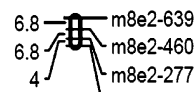

is21.7
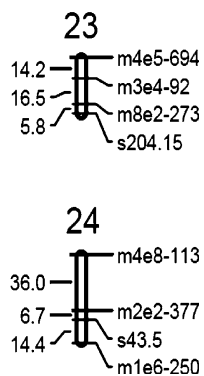

crosses between two inbred lines such as rice, maize, or soybean. Such populations are generally not available for forest trees because of time constraints. However, because of the inherent heterozygosity of single individuals, segregating progenies can already be obtained at the $F_{1}$ stage, partially circumventing the constraints. The two-way pseudo-testcross approach can be generally used to construct linkage maps. Molecular markers such as AFLPs, RAPDs, SSRs and expressed sequence tags (ESTs) polymorphisms have been used extensively for the preparation of linkage maps of a number of tree species. As a new tool, it has been helping traditional tree breeding methods through the identification of quantitative trait loci (Bradshaw and Stettler 1995) and their integration into markerassisted selection programs (Plomion et al. 1996). Recently, the functional markers, e.g., singlenucleotide polymorphisms (SNPs), have become genomic means for understanding genomic structure, as well as many other promising applications in tree 
Fig. 3 continued
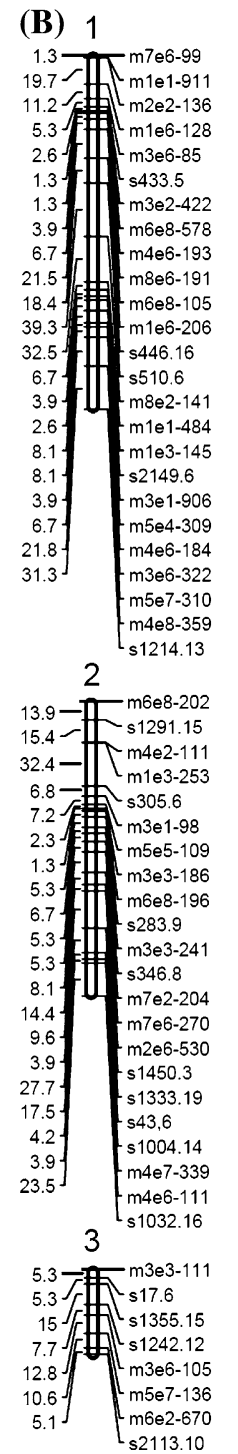
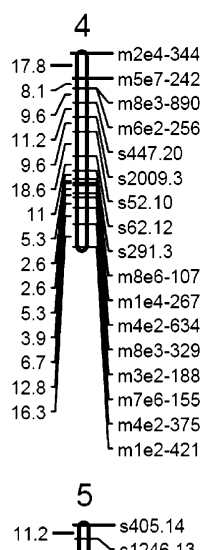

11.2 - $\$$ - 405.14

16.4

$1.37 \oiiint\left[\begin{array}{l}m 6 e 4-213 \\ m 6 e 2-186\end{array}\right.$

$\left.\begin{array}{l}2.6 \\ 5.3\end{array}\right] \mathrm{m}_{\mathrm{m} 3 \mathrm{e} 3-417}$

9.6 $\mathrm{s} 208.6$

14.4 51238.25

6.7
7.1

$\left.\begin{array}{r}7.1 \\ 21.2\end{array}\right] \begin{aligned} & \mathrm{s} 1172.15 \\ & \mathrm{~s} 26.9\end{aligned}$

$21.2] \quad\left[\begin{array}{l}\mathrm{s} 26 \mathrm{e} 8 \mathrm{-772} \\ \mathrm{m} 6 \mathrm{e} 1-321\end{array}\right.$

6
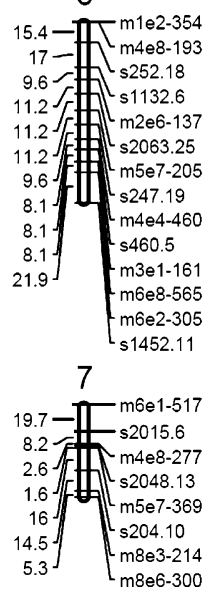
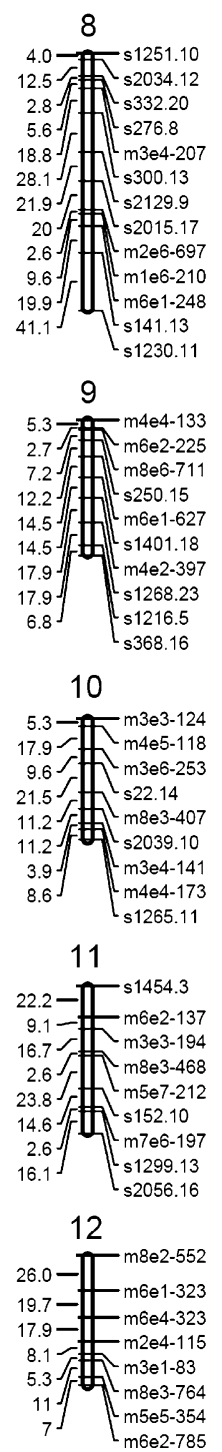
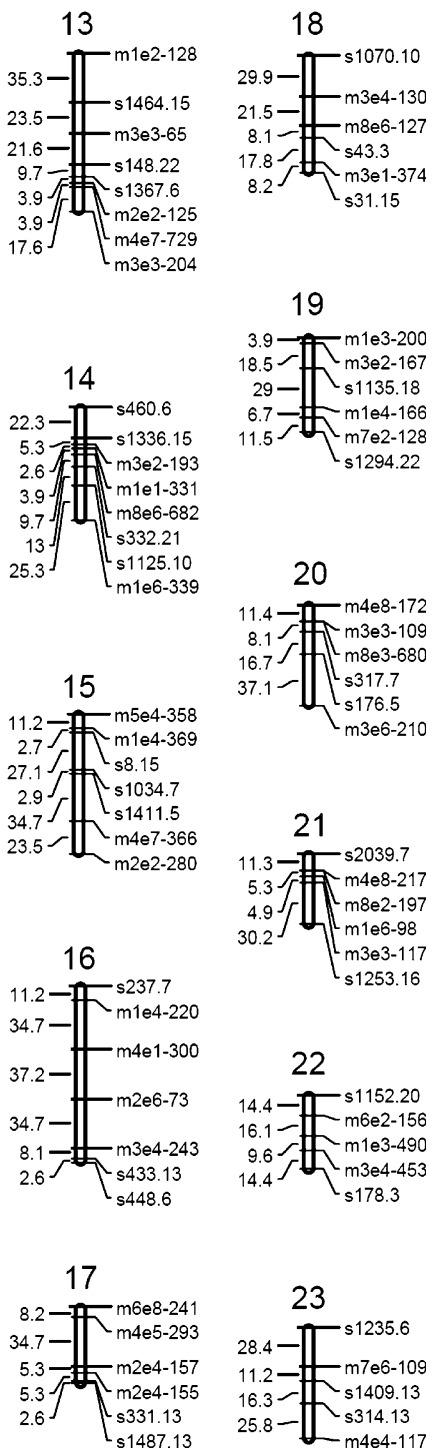

improvement (Pavy et al. 2008; Eckert et al. 2009). AFLP markers have been known for their simplicity, high sensitivity, low template DNA input and abundant polymorphisms compared to other types of markers such as RAPDs and SSRs. AFLPs are the preferred methods for revealing the genetic variances and construction of genetic linkage maps of forest trees. In tree species, the average number of AFLP fragments per primer combination has been reported to be between 6 and 26 (Arcade et al. 2000; Tsarouhas et al. 2002), while for RAPD polymorphic fragments per assay ranged from 1.3 to 4.8 (Costa et al. 2000; Kondo et al. 2001). In this study, the average number of polymorphic fragments was 13 and 1.4 for AFLPs and
RAPDs, respectively. Even though there is an issue over RAPD marker reproducibility (Isabel et al. 1999; Troggio et al. 2001), 291 reproducible polymorphic RAPD markers were used in genotyping the $F_{1}$ progeny (Fig. 1) for linkage map development in this study.

In all markers analyzed, 742 polymorphic markers, including 451 AFLP markers and 291 RAPD markers, were obtained in the present studies. Of these polymorphic markers, there were $51.6 \%$ for B. platyphylla and $48.4 \%$ for $B$. pendula, indicating a fairly even distribution among both parental lines. These observations are in agreement with the results of Yin et al. (1999) who reported the $F_{1}$ population of Populus 
Table 2 Summary of the linkage maps of Betula platyphylla and B. pendula

\begin{tabular}{|c|c|c|c|c|c|c|c|c|}
\hline \multirow{2}{*}{$\begin{array}{l}\text { Linkage } \\
\text { group }\end{array}$} & \multicolumn{4}{|c|}{ Betula platyphylla } & \multicolumn{4}{|c|}{ Betula pendula } \\
\hline & $\begin{array}{l}\text { Marker } \\
\text { number }\end{array}$ & $\begin{array}{l}\text { Max. }(\min ) \\
\text { distance }(\mathrm{cM})\end{array}$ & $\begin{array}{l}\text { Total } \\
\text { distance }(\mathrm{cM})\end{array}$ & $\begin{array}{l}\text { Average } \\
\text { distance }(\mathrm{cM})\end{array}$ & $\begin{array}{l}\text { Marker } \\
\text { number }\end{array}$ & $\begin{array}{l}\text { Max. }(\min ) \\
\text { distance }(\mathrm{cM})\end{array}$ & $\begin{array}{l}\text { Total } \\
\text { distance }(\mathrm{cM})\end{array}$ & $\begin{array}{l}\text { Average } \\
\text { distance }(\mathrm{cM})\end{array}$ \\
\hline 1 & 19 & $25.7(2.6)$ & 197.7 & 11.0 & 25 & $39.3(0)$ & 258.1 & 10.8 \\
\hline 2 & 16 & $43(1.3)$ & 272.3 & 18.2 & 22 & $32.4(0)$ & 214.7 & 10.2 \\
\hline 3 & 15 & $27.8(2.6)$ & 198.7 & 14.2 & 8 & $15(5.1)$ & 61.8 & 8.8 \\
\hline 4 & 12 & $28.4(3.1)$ & 153.5 & 14.0 & 17 & $18.6(0)$ & 141.4 & 8.8 \\
\hline 5 & 15 & $32.7(3.9)$ & 238.8 & 17.1 & 13 & $21.6(1.3)$ & 125.2 & 10.4 \\
\hline 6 & 12 & $22.7(3.9)$ & 110.5 & 10.0 & 14 & $21.9(0)$ & 131.4 & 10.1 \\
\hline 7 & 10 & $23.6(2.6)$ & 100.5 & 11.2 & 8 & $19.7(1.6)$ & 67.9 & 9.7 \\
\hline 8 & 10 & $32.7(3.6)$ & 147.6 & 16.4 & 13 & $41.1(2.6)$ & 186.9 & 15.6 \\
\hline 9 & 10 & $25.9(3.9)$ & 120.6 & 13.4 & 10 & $17.9(2.7)$ & 99 & 11 \\
\hline 10 & 9 & $23.5(2.6)$ & 66.6 & 8.3 & 9 & $21.5(3.9)$ & 89.2 & 11.2 \\
\hline 11 & 8 & $38.8(6.7)$ & 129.4 & 18.5 & 9 & $23.8(2.6)$ & 107.7 & 13.5 \\
\hline 12 & 9 & $25(5.3)$ & 115.4 & 14.4 & 8 & $26(5.3)$ & 95 & 13.6 \\
\hline 13 & 12 & $39.9(0)$ & 119.5 & 10.9 & 8 & $35.3(3.9)$ & 115.5 & 16.5 \\
\hline 14 & 10 & $33.5(0)$ & 116 & 12.9 & 8 & $25.3(2.6)$ & 82.1 & 11.7 \\
\hline 15 & 9 & $37.4(1.3)$ & 133.9 & 16.7 & 7 & 34.7 (2.7) & 102.1 & 17.0 \\
\hline 16 & 8 & $37.2(5.3)$ & 128.9 & 18.4 & 7 & $37.2(2.6)$ & 128.5 & 21.4 \\
\hline 17 & 6 & $32.8(8.6)$ & 107.8 & 21.6 & 6 & 34.7 (2.6) & 56.1 & 11.2 \\
\hline 18 & 7 & 19.7 (2.6) & 50.4 & 8.4 & 6 & $29.9(8.1)$ & 85.5 & 17.1 \\
\hline 19 & 7 & 41.9 (3.9) & 144.6 & 24.1 & 6 & $29(3.9)$ & 80.4 & 13.9 \\
\hline 20 & 6 & $15.4(0)$ & 45.3 & 9.1 & 6 & $37.1(0)$ & 73.3 & 14.7 \\
\hline 21 & 4 & $23.9(11.7)$ & 55.3 & 18.4 & 6 & $30.2(0)$ & 51.7 & 10.34 \\
\hline 22 & 4 & $6.8(4)$ & 17.6 & 5.9 & 5 & $16.1(9.6)$ & 54.5 & 13.6 \\
\hline 23 & 4 & $16.5(5.8)$ & 36.5 & 12.2 & 5 & $28.4(11.2)$ & 81.7 & 20.4 \\
\hline 24 & 4 & $36(6.7)$ & 57.1 & 19.0 & & & & \\
\hline Total & 226 & & 2864.5 & & 226 & & 2489.7 & \\
\hline Average & 9.4 & & & 14.3 & 9.8 & & & 13.1 \\
\hline
\end{tabular}

adenopoda $\times$ P. alba using RAPD markers. For linkage analysis, we used only 592 out of the 742 markers with 1:1 segregation for map construction, and in total 452 markers were linked into different groups with four or more markers per group using a minimum LOD score of 4.0. There were 59\% AFLPs and 59\% RAPDs for the linkage map of B. platyphylla and $64 \%$ AFLPs and 62\% RAPDs for the linkage map of B. pendula. The percentage of markers linked on the maps was $61 \%$ over all the polymorphic markers, which was similar with the reported map of B. pendula with $60 \%$ (Pekkinen et al. 2005).

High levels of segregation distortions have frequently been reported in tree species. The observed deviation from Mendelian expectations of a marker may be due to selection forces, sampling errors or scoring errors. In two different interspecific crosses in poplar (Cervera et al. 2001), the percentage of AFLP markers showing segregation distortion varied from 7.8 to $18.8 \%$. In Salix (Tsarouhas et al. 2002) and in Quercus (Barreneche et al. 1998), $\sim 18 \%$ and in Eucalyptus (Marques et al. 1998) $\sim 15 \%$ of the segregating loci displayed significantly skewed segregation. In this study, the distorted loci level of $9 \%$ was tolerable due to the high stringent outcrossing characteristics of Betula, presenting a high degree of self-incompatibility and inbreeding depression.

Cluster analysis revealed that 11 clusters or groups of AFLP markers in 10 linkage groups of B. pendula (Fig. 3b) existed in the present map. Keim et al. 
Table 3 Summary of the estimated genetic length and the linkage map length of Betula pendula and B. platyphylla

\begin{tabular}{|c|c|c|}
\hline Item & B. platyphylla & B. pendula \\
\hline Linkage map length $(\mathrm{cM})^{\mathrm{a}}$ & 2864.5 & 2489.7 \\
\hline Total linkage group length $(\mathrm{cM})^{\mathrm{b}}$ & 3062.6 & 2509.9 \\
\hline Estimated genetic length $(\mathrm{cM})^{\mathrm{c}}$ & 3552.7 & 3097.2 \\
\hline Linkage map coverage $(\%)^{\mathrm{d}}$ & 80.6 & 80.4 \\
\hline Total linkage group coverage $(\%)^{\mathrm{e}}$ & 86.2 & 81.0 \\
\hline
\end{tabular}

${ }^{a}$ Linkage map length $=$ the total length of the linkage groups (LGs) containing more than four markers per LG in a genetic map

b Total linkage group length $=$ the total length of all LGs including LGs with two or more markers per LG

${ }^{c}$ Estimated genetic length $=$ the sum of the length of each LG multiplied by $(m+1) /(m-1)$, in which $m(m \geq 4)$ is the number of markers included in the corresponding LG (Chakravarti et al. 1991)

${ }^{\mathrm{d}}$ Linkage map coverage $=$ the percentage of linkage map length over the estimated genetic length

e Total linkage group coverage $=$ percentage of total linkage group length over the estimated genetic length

(1997) speculated that the EcoRI/MseI-generated AFLP markers in the clusters was the result of the markers being located in regions of reduced recombination, most likely near centromeres. Reasons given for this included a higher frequency of polymorphisms in these regions, because they are mainly noncoding sequences, and the use of MseI that cuts more frequently in high $\mathrm{A}+\mathrm{T}$ regions due to its restriction sequence (Alonso-Blanco et al. 1998). In contrast, the Pst-AFLP markers were generally mapped to regions containing a lower density of markers. On the other hand, EcoRI and PstI differ greatly in their ability to cut restriction sites containing methylated cytosine (C). Pst I is greatly inhibited by $\mathrm{C}$ methylation whereas EcoRI is relatively insensitive to $\mathrm{C}$ methylation. These facts suggested that the restriction enzyme used in AFLP analysis can bias marker distribution to different regions, probably due to genomic methylation patterns and $\mathrm{A}+\mathrm{T}$ contents. These results suggested that the enzymes used to generate the AFLP markers influenced their genomic distribution (Young et al. 1999).

As diploid species, B. platyphylla and B. pendula have 14 pairs of chromosomes $(2 \mathrm{n}=28)$. Pekkinen et al. (2005) reported that the linkage map of B. pendula contains 16 linkage groups consisting of two or more loci, and the estimated genome size ranged from 1,906 to $3,589 \mathrm{cM}$. The closely related tetraploid B. pubescens has a genome size of $1.4 \mathrm{pg}$ (2C DNA) (Grime and Mowforth 1982). In this study, the estimates were 3552.7 and $3097.2 \mathrm{cM}$ for $B$. platyphylla and B. pendula, respectively (Table 3 ). Thus, the 226 markers placed in both current linkage maps or the total of 253 and 233 markers representing the total linkage groups only covered $81.0-86.2 \%$ of the estimated genetic length of the white birch genome. It is difficult to estimate how large a fraction of the genome is thereby covered, because the total genetic length of the genome is still unknown. Nevertheless, additional markers are needed to fill the gaps and improve the genetic maps for Betula, along with increasing the population size and the development of additional markers and the types of markers. A high density linkage map is crucial for QTL analysis, molecular marker-assistant selection, and map-based cloning. Currently, we are developing more markers such as SSRs and SNPs in order to increase the density and quality of the map for Betula. A high-density genetic map of birch is achievable by integrating AFLP markers with SSRs and SNPs when more genomic resources are readily available. Genetic linkage mapping has become a necessary tool for genome analysis and molecular genetic breeding in forest trees (Grattapaglia and Sederoff 1994). These two maps will establish a basis for developing a more detailed linkage map and potential molecular marker-assisted selection for white birch trees. The construction of a high density genetic linkage map can serve as a foundation for map-based cloning and should facilitate markerassisted selection of desired alleles or traits in white birch breeding.

\section{References}

Alonso-Blanco C, Peeters AJM, Koornneef M, Lister C, Dean C, van den Bosch N, Pot J, Kuiper MTR (1998) Development of an AFLP-based linkage map of Ler, Col and Cvi Arabidopsis thaliana ecotypes and construction of a Ler/Cvi recombinant inbred line population. Plant J 14:259-271

Arcade A, Anselin F, Faivre RP, Lesage MC, Pques LE, Prat D (2000) Application of AFLP, RAPD and ISSR markers to genetic mapping of European and Japanese larch. Theor Appl Genet 100:299-307

Barreneche T, Bodenes C, Lexer C, Trontin JF, Fluch S, Streiff R, Plomion C, Roussel G, Steinkellner H, Burg K, Favre JM, Glossl J, Kremer A (1998) A genetic linkage map of 
Quercus robur L. (pedunculate oak) based on RAPD, SCAR, microsatellite, minisatellite, isozyme and $5 \mathrm{~S}$ rRNA markers. Theor Appl Genet 97:1090-1103

Bradshaw HD, Stettler RF (1995) Molecular genetics of growth and development in Populus. IV. Mapping QTLs with large effects on growth, form and phenology traits in a forest tree. Genetics 139:963-973

Cervera MT, Storme V, Ivens B, Gusmao J, Liu BH, Hostyn V, Van Slycken J, Van Mantagu M, Boerjan W (2001) Dense genetic linkage maps of three poplar species (Populus deltoids, P. nigra and P. trichocarpa) based on AFLP and microsatellite markers. Genetics 158:787-809

Chakravarti A, Lasher LK, Reefer JE (1991) A maximum likelihood method for estimating genome length using genetic linkage data. Genetics 128:175-182

Costa P, Pot D, Bubos C, Frigerio JM, Pionneau C, Bodenes C, Bertocchi E, Cervera MT, Remington DL, Plomion C (2000) A genetic map of Maritime pine based on AFLP, RAPD and protein markers. Theor Appl Genet 100:39-48

Eckert AJ, Bower AD, Wegrzyn JL, Pande B, Jermstad KD, Krutovsky KV, Clair JBS, Neale DB (2009) Association genetics of coastal douglas fir (Pseudotsuga menziesii var. menziesii, Pinaceae). I. Cold-hardiness related traits. Genetics 182:1289-1302

Grattapaglia D, Sederoff R (1994) Genetic linkage maps of Eucalyptus grandis and Eucalyptus urophylla using a pseudo-testcross: mapping strategy and RAPD markers. Genetics 137:1121-1137

Grattapaglia D, Sederoff R (1995) Genetic mapping of QTLs controlling vegetative propagation in Eucalyptus grandis and E. urophylla using a pseudo-testcross mapping strategy and RAPD markers. Theor Appl Genet 90:933-947

Grime JP, Mowforth MA (1982) Variation in genome size-an ecological interpretation. Nature 299:151-153

Isabel N, Beaulieu J, Theriault P, Bousquet J (1999) Direct evidence for biased gene diversity estimates from dominant amplified polymorphic DNA (RAPD) fingerprints. Mol Ecol 8:477-483

Jiang J, Yang CP, Liu GF, Liu YX, Ren XQ (2001) Analysis of genetic variation within and among Betula platyphylla provenances and provenance division using RAPD markers. Bull Bot Res 21:126-130

Jiang J, Yang CP, Liu GF, Liu YX, Ren XQ (2002) Analysis of genetic relationship of Betula among species using RAPD marker. Sci Silv Sin 38:154-156

Keim P, Schupp JM, Travis SE, Clayton K, Zhu T, Shi L, Ferreria A, Webb DM (1997) A high-density soybean genetic map based on AFLP markers. Crop Sci 37: 537-543

Kondo T, Terada K, Hayashi E, Kuramoto N, Okamura M, Kawasaki H (2001) RAPD markers linked to a gene for resistance to pine needle gall midge in Japanese black pine (Pinus thunbergii). Theor Appl Genet 102:871-875

Kulju KKM, Pekkinen M, Varvio S (2004) Twenty-three microsatellite primer pairs for Betula pendula (Betulaceae). Mol Ecol Notes 4:471-473

Lander ES, Green P, Abrahamson J, Barlow A, Daly MJ, Linconln SE, Newburg L (1987) Mapmaker: an interactive computer package for constructing primary genetic linkage maps of experimental and natural populations. Genomics 1:174-181
Li P, Fang GP, Sun CZ (1995) Wood characteristics of pulp wood III. Chem Ind For Prod 15(Suppl):13-18

Liu RH, Meng JL (2003) MapDraw: a Microsoft excel macro for drawing genetic linkage maps based on given genetic linkage data. Hereditas (Beijing) 25:317-321

Marques CM, Araujo JA, Ferreira JG, Whetten R, O’Malley DM, Liu BH, Sederoff R (1998) AFLP genetic maps of Eucalyptus globulus and E. tereticornis. Theor Appl Genet 96:727-737

Mutikainen P, Walls M, Ovaska J, Keinanen M, JulkunenTiitto R, Vapaavuori E (2000) Herbivore resistance in Betula pendula: effect of fertilisation, defoliation and plant genotype. Ecology 81:49-65

Myburg AA, Remington DL, O'Malley DM, Sederoff RR, Whetten RW (2001) High-throughput AFLP analysis using infrared dye-labeled primers and an automated DNA sequencer. BioTechniques 30:348-357

Pavy N, Pelgas B, Beauseigle S, Blais S, Gagnon F, Gosselin I, Lamothe M, Isabel N, Bousquet J (2008) Enhancing genetic mapping of complex genomes through the design of highly-multiplexed SNP arrays: application to the large and unsequenced genomes of white spruce and black spruce. BMC Genom 9:21

Pekkinen M, Varvio S, Kulju KKM, Kärkkäinen H, Smolander S, Viherä-Aarnio A, Koski V, Sillanpää MJ (2005) Linkage map of birch, Betula pendula Roth, based on microsatellites and amplified fragment length polymorphisms. Genome 48:619-625

Plomion C, Durel CE, O’Malley D (1996) Genetic dissection of height in maritime pine seedlings raised under accelerated growth conditions. Theor Appl Genet 93:849-858

Tammisola J, Varhimo A, Velling P, Vihera-Aarnio A, Kauppinen V, Sundouist J, Lapinjoki S (1995) Variation in the wood and pulping properties of European white birch. Paper and Timber 77:641-648

Troggio M, Kubisiak TL, Bucci G, Menozzi P (2001) Randomly amplified polymorphic DNA linkage relationships in different Norway spruce populations. Can J For Res 31: 1456-1461

Tsarouhas V, Gullberg U, Lagercrantz U (2002) An AFLP and RFLP linkage map and quantitative trait locus (QTL) analysis of growth traits in Salix. Theor Appl Genet 105:277-288

Vos P, Hogers R, Bleekers M, Reijans M, van der Lee T, Hornes M, Frijters A, Pot J, Peleman J, Kuiper M, Zabeau M (1995) AFLP: a new technique for DNA fingerprinting. Nucleic Acids Res 23:4407-4414

Wei ZG, Yang CP, Pan H (2006) Identification of molecular markers associated with birch fiber length trait by multiple regression analysis. Mol Plant Breed 6:835-840

Wu B, Lian C, Hogetsu T (2003) Development of microsatellite markers in white birch (Betula platyphylla var. japonica). Mol Ecol Notes 2:413-415

Yin TM, Huang MR, Zhu LH (1996) Using dominant markers and $F_{1}$ pedigree to construct genetic linkage map in forest trees. Prog Biotechnol 16:12-16

Yin TM, Huang MR, Wang MX, Zhu LH, He P, Zhai WX (1999) RAPD linkage map in a Populus adenopoda $\times$ P. alba $\mathrm{F}_{1}$ family. Acta Bot Sin 41:956-961

Young WP, Schupp JM, Keim P (1999) DNA methylation and AFLP marker distribution in the soybean genome. Theor Appl Genet 99:785-790 